\title{
A Study on the Model of College English Translation Workshop based on Blended Teaching
}

\author{
Junming Xiao \\ Qiqihar Medical University, Qigihar City, Heilongjiang Province, 161006, China
}

Keywords: College English, Translation teaching, Workshops, Blended Teaching.

\begin{abstract}
Blended teaching is not a new teaching method or theory, but with the deepening of educational information, it has gradually received widespread attention. Blended Teaching advocates combining the advantages of traditional teaching with the advantages of Digital Teaching, so as to achieve a better teaching effect. Based on the author's research on Blended Teaching, this paper introduced a new model of College English translation teaching - Workshop. The author first analyzed the translation workshop classroom model, then put forward the suggestions on the implementation of English Translation Workshop Teaching.
\end{abstract}

\section{Introduction}

From the purpose of teaching, the cultivation of translation ability is very necessary. Economic globalization has greatly increased the demand for translation talents, especially those of scientific and technological translators, who are mainly from non English majors with professional backgrounds. A few foreign language graduates can no longer meet the social demand for translation talents. However, there are many disadvantages in the teaching of College English translation, and the students' translation ability is not optimistic. Therefore, it is necessary to reform the traditional college English translation teaching. In this regard, "translation workshop" can provide us with a useful perspective of teaching practice.

\section{The Workshop Translation Classroom Model}

Introducing workshop model into translation classroom teaching can make the classroom teaching break through the traditional teaching mode. Dividing the translation class into multiple translation workshops enables workshops to organize activities and create an active classroom atmosphere, which greatly improves the students' interest in learning translation. A workshop model introduced by translation classroom describes the application process, and the following is attempted in accordance with figure 1 :

The translation teacher conducts a thorough examination before the beginning of the course. According to the principles of grades, character, gender and willingness of students, they are divided into a group of three to five small workshops in the translation class. In the translation class, the workshop members sit together in order to carry out various activities, games and contests in the translation classes. (Of course, this workshop can be adjusted appropriately in class.) Before class or in class (such as the subject or project has been determined in advance), assignments are made among the members of each workshop (each member's task is not fixed, and the tasks of each member are often changed and adjusted) to form cooperation. In view of the fact that many students have no cooperative learning experience at the beginning and do not know how to communicate with the workshop members, so the teacher should teach students some basic skills or some training to improve the quality of cooperation in advance. The positive activities between workshops will influence each other, learn from each other and promote each other. In the process of practice, students also build a sense of teamwork and cooperation. 


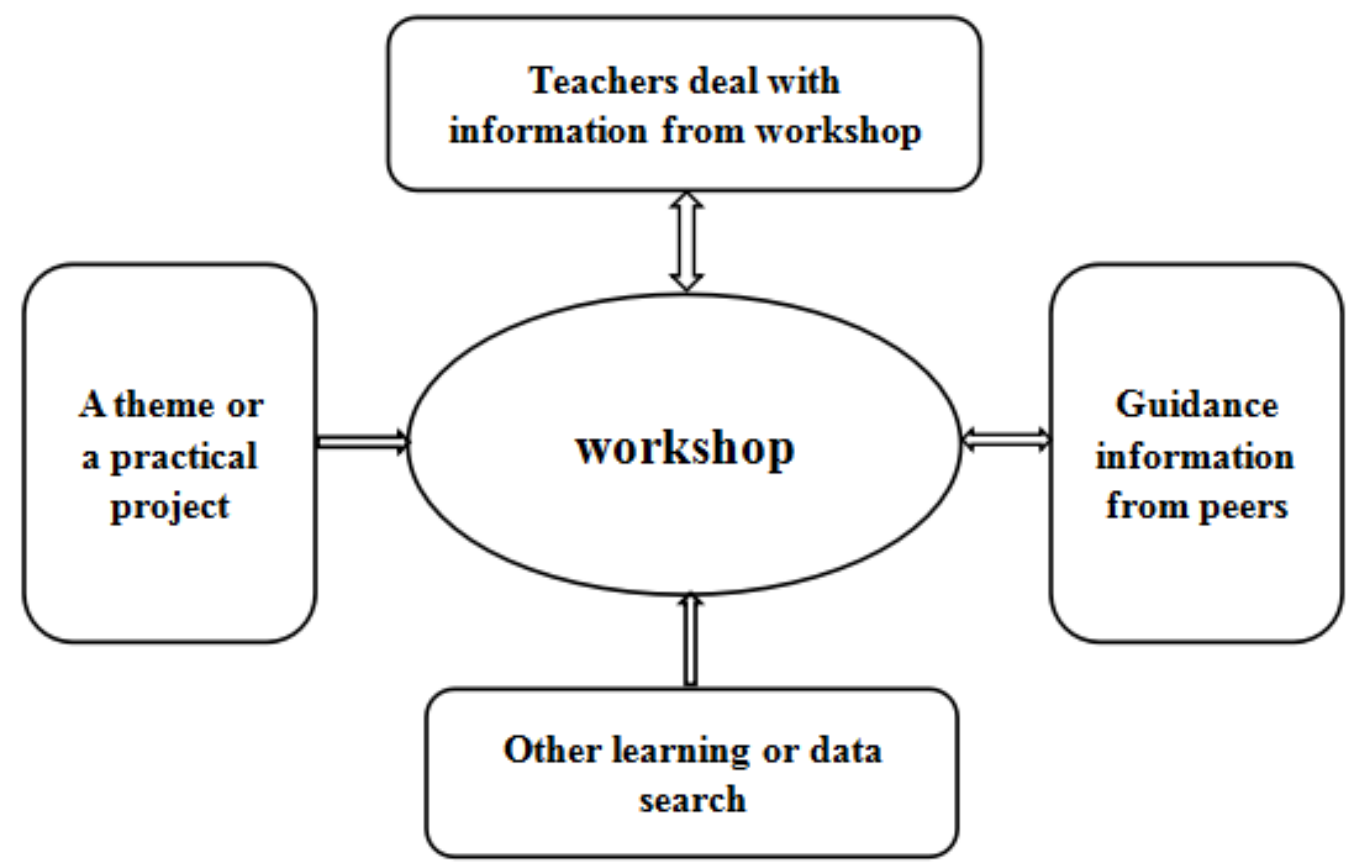

Fig.1 Workshop model of the Translation Classroom Teaching

In general, a teacher is both a tutor and a director. Before each class, the teacher determines the topic aiming at the content; they provide the project based on practices of themselves and colleges; according to student characteristics and the workshop feedback, they plan classroom operations; they prepare the relevant props and various types of materials according to class needs, and ensure that they are proficient in the class process going to be carried out; in class, the teachers organize workshops to carry out activities positively and take control of the situation. Therefore, it has put forward higher requirements for the translation class teachers. They need to have sufficient knowledge, experience in translation, participation spirit, organization ability, quick response and adaptability. In addition, it is necessary to invite different first-line translators to participate in classroom activities, lectures, seminars and so on. Teachers communicate with different translators; they especially teachers also need to keep track of the feedback from the workshop.

Topics and projects of the workshop are the basic direction that lead the students to learn and practice. These topics are knowledge or skills that must be mastered in the course of translation. Some of these projects are the translation projects undertaken by teachers or translators in this field. The teacher guides the students in related work. Some projects are simulated translation projects for students according to the course of students' learning and the actual work. Almost all of the students' practical activities are targeted at one component of a specific project or project. In the course of real work, students understand and learn relevant knowledge and improve their application skills. The introduction of workshop model into translation classroom teaching provides an approximate realistic translation task and collaborative approach. In a relaxed atmosphere, we can provide students with the whole process of learning what they have learned, effectively cultivating the students' practical translation ability, so that the translation classroom teaching will form a "teaching, practice, research" trinity of good teaching model.

\section{Suggestions on the Implementation of English Translation Workshop}

Translation workshop needs scientific positioning. The positioning of the English translation workshop is the key to success. The goal of the workshop is to provide a good platform for translation teaching rather than a profitable studio. Based on this positioning, the workshop should avoid receiving a large number of low-level translation tasks in the selection of translation tasks, and should select appropriate quality tasks according to students' different learning stages. Controlling the size and quality will ensure that students focus on learning and improvement and ensure the positioning of the workshop. 
Teaching activities should lead the workshop daily operation. Teaching based on workshop must solidify the most basic teaching actions into the routine of the workshop. The students' study time has a strict schedule, and the translation teaching will be a fixed time in the weekly timetable. Therefore, the workshop is not a routine enterprise; it is only a source of teaching resources, and is the implementation platform of teaching action and application. At weekly fixed teaching time, it can focus on the typical translation case of this week, and combine theoretical knowledge with practical application. On the one hand, it is an "evaluation and summary" of the work done by the workshop; on the other hand, it is also a training for students' "working skills". The purpose of the workshop is to teach, and translation tasks need to be carefully chosen and controlled. For each student, the school is unable to control its personal time to receive translation work from outside the school. But in the workshop, the amount of work that students have to obtain at each stage of the study must be appropriate with high quality. After the completion of each translation task, students must evaluate their work and the works of their classmates, so as to find out the highlights and shortcomings of each exercise. Only when the teaching actions are carried out in translation practice, can students be assured that they will not be thinking and improving mechanically.

Student behavior needs to be strengthened. In fact, a large number of students are part-time translator at present. Therefore, the significance of establishment of English translation workshop mainly lies in the combination of teaching and application. This provides a better translation material for students, and brings benefits for them. After the establishment of translation workshop, translation "business" volume will rise rapidly. Thus, the students could lose their way easily and spend much valuable time on making money. Therefore, how to guide and manage students to arrange their time and balance their benefits and losses is the key to the continuous operation of the workshop. After all, schools, parents and students themselves do not want to see personal growth for the sake of short-term economic gain. In actual operation, we consider whether we should continue to involve students in the translation workshop through the examination and observation of normal students learning. If students devote too much energy to earning extra income, other developments are bound to be affected. At this point, we can take the opportunity to reduce the allocation of tasks or reduce their access to high-level translation resources, so that to give warnings to them.

Choose translation content in a clever way. From a more innovative point of view, the translation workshop can completely integrate the teaching content of other subjects required or selected by the students on the basis of translation teaching. If the above analysis, students must understand the content of translation in depth, so that to translate the perfect works in the process of translation research. Therefore, we should target the content of other subjects related to students in selecting translation tasks. For example, there are many professional materials in the courses of economic management and financial accounting, such as news reports, analysis and reports. Students can rapidly learn related knowledge through translating these materials. The originally obscure terminology combined with the practical phenomenon in translation practice discussion will become vivid and easy to be understand. In the discussion and research process, it not only improves the ability of translation, but also synchronously learns other courses. This can kill two birds with one stone.

Coordinate the relationship between teaching and interest. From the point of view of input and output, translation workshops can bring certain economic benefits to schools and students. Therefore, it is necessary to coordinate the interests of all parties concerned. We regard improvement of translation ability and brand as core, and maintain the returns of the students. We also conduct an entrepreneurial management of the performance and output of students in the workshops. For the "employer", they want the mission given to school to be able to rely on the school professional background, so that to output high quality translation. If school casually manage such situation, there will be many translations with low quality. This not only damages the interests of the "employer", but also impairs the image of the school. For example, the school should obtain the customer's feedback record and record it in the author's assessment record for each task. According to the difficulty level and user task evaluation, schools should judge students' abilities 
and rewards, and judge whether they need to adjust their work schedules.

\section{Summary}

As for the success of any application-oriented teaching mode, its core is the energy input and the effect of the balance. There is no doubt that English translation teaching is bound to enhance students' ability in translation through the practice of workshops. However, it is not enough to only rely on translation or English as their capital. Especially in the trend of English popularity, English has gradually become the most basic tools, and the employment and development of English majors will face a severe adjustment. Therefore, students can not sacrifice too much precious time in the workshop, and we should remind students to improve their comprehensive quality to meet the needs of society.

\section{Acknowledgement}

Research subject of educational science in Qiqihar Medical University(QYJY20170105).

\section{References}

[1] Fu Yalin. Analyze the Effective Teaching Mode of College English Translation Course[J]. Shandong Social Sciences, 2016, (S1): 534-535.

[2] Yang Yanjun, Li An. An Experimental Study of Workshop Model Embedded in English Translation Teaching[J]. Education Academic Monthly, 2015, (12): 97-103.

[3] Wang Yan. Translation Workshop in Translation Teaching of Undergraduate English Majors in Application[D]. Inner Mongolia Normal University, 2013.

[4] Ai Mina. A Study on the Practice Model of "Workshop" Business English Translation Teaching[J]. Journal of Jilin Institute of Education (Early), 2013 (04): 65-66.

[5] Zhang Xiao. Study on the Effective Teaching Mode of English Translation Course in College[J]. Education and Occupation, 2011, (26): 104-105.

[6] Huang Yue. The application of workshop model in English translation class teaching[J]. Journal of Linyi University, 2011, (02): 62-64.

[7] Li Lin. Construction of Task-based Translation Teaching Model in College English[J]. Crazy English (Teacher Edition), 2009, (06): 63-65+78. 